\title{
Application of Constructivist Theory in Flipped Classroom - Take College English Teaching as a Case Study
}

\author{
Ziling Xu \\ Zhejiang Ocean University, Zhoushan, China \\ Yeli Shi \\ Zhejiang Ocean University, Zhoushan, China
}

\begin{abstract}
In the context of information globalization and the popularity of the Internet, the flipped classroom as a new teaching mode, a new pedagogical method has become a heated topic and a growing concern for educators across the world. In this paper, the flipped classroom is supported by constructivist learning theory. The teaching mode under the constructivist learning theory is typically students-centered which corresponds with the flipped classroom mode. This paper mainly focuses on the application of constructivist learning theory in flipped classroom, taking college English teaching for example to interpret the student- student, teacher- student interactions in the flipped classroom with the final goal to promote students' learning efficiency and quality.
\end{abstract}

Index Terms - flipped classroom, constructivist learning theory, self-directed learning, college English teaching

\section{INTRODUCTION}

Traditional classroom teaching mode is a one-way process that teachers, guided by certain teaching goals in certain teaching places, pass on human beings' existing cultural knowledge to the educated (students) through indoctrination. In this mode, teachers just rely on a textbook, a reference book, a piece of chalk, and a mouth to carry out the education teaching activities with goals, plans and emphasis in accordance with the principle of teaching theory and in the form of classroom teaching. This kind of teaching is teacher-centered, and the students' knowledge acquisition depends on the teacher's imparting and guiding (Luo, 2012).

The rapid development of information technology brings the infinite possibility of education. The popularity of the Internet has changed the way people work and live, as well as the way of education and learning ( $\mathrm{Li}, 2016)$. The flipped or inverted classroom teaching mode refers to the re-adjustment of time in and out of the classroom, transferring the decision of learning from the teacher to the student. Under this teaching mode, students will be able to concentrate more on the initiative of project-based learning, and gain a deeper understanding during the precious class time. Teachers no longer just take the classroom time to pass on information but guide students. The role of a teacher is the faithful supporter of students' construction of knowledge and the facilitator and collaborator of students' learning. The required or relevant information should be prepared by students or through watching video lectures, listening to podcast or reading e-books out of class. They can also discuss with other classmates through the Internet and consult the materials they need at any time. In this case, teachers may have more time to communicate with everyone in class and pay more attention to the individual one.

As Bergmann and Sams (2012) have described that the flipped or inverted classroom is an instructional model in which the traditional lecture is a student's homework and in-class time is spent on collaborative, inquiry-based learning. Felder (2012) showed his view as this: student-centered instructional models, including the flipped classroom, are grounded in the constructivist theory of learning. The core idea of constructivism applied to learning is that the environment is learner-centered where knowledge and understanding is socially constructed. The flipped classroom environment can be totally considered a constructivist learning environment. The constructivist learning theory advocates the student-centered learning under the guidance of teachers. Besides, constructivist learning environment includes four elements: situation, cooperation, conversation and meaning construction. In this way, we can summarize the teaching mode that adapts to the constructivist learning theory and constructivist learning environment as follows: In the course of the whole learning process, teachers will play the role of organizer, mentor, helper and facilitator while students are placed at the center. Situation, cooperation and conversation are used as learning environment elements to completely stimulate the initiative, enthusiasm and the pioneering spirit of students. Thus, it can finally achieve the purpose of effectively realizing the meaning construction of the current knowledge (He, 1997). In this mode, students are active constructors of knowledge rather than passive recipients of external stimuli; and the teacher is the facilitator of the instructional process, rather than the teacher of knowledge. The knowledge provided by the textbook is no longer 
the content of the teacher's teaching, but the object of the students' active construction of meaning. Media is no longer the means for helping teachers pass on knowledge, but to create a situation in collaborative learning. Conversation is used as one of the students' collaborative and exploratory learning tools. On this occasion, four elements including teachers, students, teaching materials and media, compared with the traditional teaching method, have their own different roles and completely different relationships between each other. But the role and relationship are definitely clear. Through the process of teaching activities, or under the constructivist learning environment, the relationship has gradually become a stable structure.

\section{RESEARCH ON FliPPED ClaSSROOM TEACHING Mode}

Flipped classroom is a new kind of teaching method that completes the transmission of knowledge outside classroom and realizes the internalization within the classroom. Throughout the world, there has been a boom in research on flipped classroom teaching mode both at home and abroad.

\section{A. Researches Abroad}

As the new pedagogical method of flipping the class has been popular for decades in foreign education, abundant researches have been conducted in this field and fruitful research findings have come out (Wang, 2017). In recent years, the research on flipped classroom has a high degree of heat. Foreign research on flipped classroom started earlier. Before 2005 the study focused on the patterns of flip classroom, and since 2010 it has been concerned more about such aspects as active learning, and blended learning, some research areas mainly covering medical education in tertiary education. In terms of active learning and blended learning, foreign studies have adopted the quasi-experimental research method. The influence of flipped classroom on students' emotion and behavior is explored through the analysis of pre-test. Richard Pearce et al. (2012) used video blog to develop classroom teaching, and cultivate the students' active learning ability. The results showed that students not only improved their grades, but also had positive views on teaching methods. Paul Barpule et al. (2014) found that learning in a mixed learning way could be no less effective than traditional classroom learning and improve students' cognition of learning environment. Developed countries like the United States and Australia have high popularity of flipped classroom research, which indirectly indicates that the research on flipped classroom is relevant to the education degree and reform requirements of the country. Those countries mainly promote active learning and blended learning based on flipped classroom. Besides, the researches abroad are more focused on application studies, using quasi-experiment for evaluation. Through comparison before and after the test, they focus on students' performance and the improvement of problem solving, information literacy, critical thinking, and collaborative learning ability (Wang, Huang\& Jiang, 2017).

\section{B. Researches in China}

The researches of flipped classroom in China are mainly combined with Micro-course Mooc to construct teaching models and work out optimum teaching designs and so on. To localize flipped classroom, Professor He Kekang (2014) fought to analyze the origin and the effect of classroom and challenges which may exist in implementation, and explored the essential characteristics of the flipped classroom. He put forward a clear guidance for the development of flipped classroom in China. Dr. Zhao Xinglong (2014) compared the flipped classroom in the international and domestic contexts, and designed the flipped classroom teaching mode from the perspective of macro and micro. To design the flipped classroom and attract the students' attention, Zhang Jinlei (2013) put forward three stages of flipped classroom based on the concept of game-based teaching and flipped classroom teaching mode. Chen yi et al. (2014) took the basic course of computer application as an example to design a flipped classroom teaching plan which included two stages of flipped classroom model before and after class.

By constructing the flipped classroom teaching model and using educational resource, China aims to optimize teaching design, such as Micro-course Moocs. On the research type, there are more theoretical studies in China and in terms of evaluation dimensions, questionnaires and interviews are adopted to know about teachers and students' recognition of the curriculum, students' interest, participation, and their concern about the course. Flipped classroom teaching is frequently applied to the courses of computer, foreign language, and literature, Marxist theory and so on. More attention is paid to the paradigm of design research, from design to practice, and to the revision or improvement of original design or mode model. Currently in ubiquitous learning environment, flipped mode as the basis is used to promote blended learning, strengthen the combination of the online and offline. Through online self-learning and offline interaction between teachers and students, students' internalization of knowledge and the process of knowledge construction are emphasized (Wang, Huang\& Jiang, 2017).

\section{FlipPed Classroom Teaching Mode}

Advances in information technology have revolutionary influence on the development of education. With the informationization of education, flipped classroom teaching mode has been widely popularized and applied.

\section{A. Defining the Flipped Classroom}

Despite the buzz around the flipped classroom as an exciting new topic in educational research, there is a lack of 
consensus on what exactly the flipped classroom is. Perhaps the simplest definition of the flipped, (or inverted) classroom is given by Lage et al. 'Inverting the classroom means that events that have traditionally taken place inside the classroom now take place outside the classroom and vice versa' (Bishop \& Verleger, 2013). The exposition of Hamdan et al. is more comprehensive. 'In the flipped learning environment, teachers provide students with video, which is convenient for them to watch and learn from time to time, so as to make them more efficient learners. Because the direct teaching process of knowledge is transferred from class to outside, teachers can use class time to guide students to active participation in the learning process and provide them with personalized guidance and support' (Li, 2016). The idea of flipping the classroom with resources like the Khan Academy is simple. Rather than the teacher provides synchronous in-class group instruction, students are expected to use the video resources provided, along with other materials, to learn concepts and complete tasks independently at their own pace and at locations convenient to students. Individual students can focus their efforts on their individual learning needs so that they are not left behind by class discussions that go too fast or become bored by class time that is spent covering content they have already known (Davies, Dean\& Ball, 2013).

Nevertheless, there are misconceptions towards the understanding of the flipped classroom. Some people equate it with online video or online courses, thinking video courses will completely replace teachers, thus students' learning is isolated without a framework. As the earliest practitioners of flipped classroom, to prove its feasibility as a teaching method, Bergmann and Sams (2012) listed several characteristics of the flipped classroom teaching mode as follows: it is the means to increase the interaction between teachers and students and can encourage students to be responsible for their learning environment. In the class, teachers transfer their role from 'the sage on the stage' to 'the mentor around' with the integration of direct teaching method and constructivist learning idea. Students can keep up even if they miss classes because of illness or extracurricular activities. Besides, with this mode, teaching resources can be kept at any time for students and students can be fully engaged in the learning process. Then, it provides students with a shortcut to a personalized education $(\mathrm{Li}, 2016)$.

\section{B. The Rise and Application of Flipped Classroom Teaching Mode}

As a new paradigm of classroom teaching, flipped classroom can be traced back to the Peer Instruction method founded by Harvard University physics Professor Eric Mazur in 1990. He proposed that the learning process should include knowledge transfer and knowledge reception. Professor Mazur asked students to teach themselves about course content outside class while in class, he mainly took the teaching method of 'asking questions--thinking--answering' and some other interactive activities. The first to propose the conception of 'flipped classroom' were Maureen J. Lage and Glenn J. Platt, who taught at the University of Miami's Business School. They defined the flipped classroom as this: The teaching and learning activities that have been carried out in the classroom are put into practice before class, and the reverse is still true. As a matter of fact, not only did they define the flipped classroom, but in 1996 flipped classroom instruction was applied to the micro-economics course for sophomores. This course turned the flipped classroom concept into the instruction, which first divided the teaching materials according to the subject, and then let students use their free time after class independently to read some related subject contents, and watch the video as well as the corresponding teaching courseware.

The real initiators of flipped classroom are Jonathan Bergmann and Aaron Sams. The two chemistry teachers at Woodland High School in Colorado, US, started the flipped classroom in 2007 by a chance of attempt, and later it has gone through the rapid development. They thought the class time was mainly used to teach the students to do exercises, solve students' doubt, tutor students in cooperative learning and the differential learning between groups. Before class, students must finish viewing the already uploaded teaching micro video. As they took the 'World Flipped Classroom Open Day' activities regularly, the concept of flipped learning was deeply rooted in the hearts of the people and vividly shown in public. Besides, more and more primary and secondary schools in the United States began to participate in the application of flipped classroom practice. The impact of the flipped classroom was pushed to the world by Salman Khan, founder of Khan Academy, who made his famous TED speech--- using video to recreate education in 2011 which made the flipped classroom begin to get the attention of global educators. By 2012, there were nearly a thousand of primary and middle schools in North America to carry out practical application of flipped classroom teaching mode (Dai, 2016).

The flipped classroom emphasizes the interaction between teachers and students and focuses on the self-learning and collaborative exploration based on resources, and pays special attention to the acquisition process of knowledge rather than the teaching of teachers. The rapid development of information technology brings the infinite possibility of education. The OpenCourseWare project, which was launched in 2002 by the Massachusetts Institute of Technology, broadened the breadth of education resources to the academic authority of education. MIT alumni Salman Kahan made full use of the convenience of network transmission and the low cost of video reuse. Since the teaching of knowledge points can be reached through prerecorded video, valuable classroom time is invested in irreplaceable teacher-student interactions and classroom activities based on project and problem solving. This is also the core of flipped classroom teaching idea ( $\mathrm{Li}, 2016)$. The flipped classroom which is equipped with a variety of technologies, like video and online automatic response systems has brought about great changes in the following aspects ( Bishop \& Verleger, 2013; Abeysekera \& Dawson, 2014; Kim et al., 2014): the way classroom time was used, the approach of utilizing extra-curricular time, the use of class, and the form of interaction. 


\section{The Presentation of Flipped Classroom Teaching Mode}

The advantage of the flipped classroom teaching mode is that it can transfer the process of knowledge acquisition in the traditional classroom into the process of students' autonomous learning knowledge before class. In class, they only explore and solve the confusion and difficulties of some certain knowledge points. This process is conducive to students' autonomous learning. It carries out the flip both before and in class and cultivates students' learning initiatives. There can be two types of the presentation of flipped classroom teaching mode: flip before class and flip in class.

First, about the presentation of flipping before class. Students need to learn the lesson and other related information before class, have a basic understanding of major knowledge, complete the inspection, summarize the gain in learning and think for the confusion of knowledge points, and then solve the difficulties with teachers and classmates in the classroom. Teachers need to offer Micro-Course Online Video and study guides to students, and students study before class. Next, about the presentation of flipping in class. Based on the students ' learning outcome before class, students in the classroom are required to consolidate the fundamental knowledge, solve problems and take some practical operations, as appropriate to the grasp of knowledge or to expand exploration, and develop comprehensive quality. The class is in essence switched into the venue of training students' abilities of researching and thinking on the basis of mastering basic knowledge. The presentation is featured by teachers and students' joint determination of questions and inquires and students' independent settlement of problems in addition to teachers' guidance in students' performance of collaborative exploratory activities. Ultimately, the presentation is fulfilled by students' display and teachers' evaluation and feedback ( Fang, 2017).

\section{CONSTRUCTIVIST Learning THeORY}

In flipped classroom, students are the main body of cognition, the center of the whole class, and the active constructors of meaning construction which breaks through the limitations of traditional classroom. Before class, students preview the relevant knowledge through some online media to have their autonomous meaning construction. Such a teaching mode of flipped classroom is carried out by the constructivist learning theory which holds the opinion that students are active constructors of meaning, the leader and controller of the learning process while teachers only assist students in developing their autonomous learning.

\section{A. Defining the Constructivist Learning Theory}

Felder (2012), Gordon (2008), Neo et al.(2009) hold the opinion that constructivism has emerged as a powerful theory for explaining how humans learn about the world around them and how new knowledge is formed. The theory of constructivism is that knowledge is not waiting to be discovered but rather it is constructed by humans by interaction with the world and with each other. Learner collaboration, interaction, and engagement are foundational in the constructivist theory of learning. Carini, Menchaca, Merril et al. think that collaborative, interactive activities have been touted to be most effective at helping students reach a higher level of understanding (Butzler, 2014). The constructivist learning theory states that through consultation in the community, learning can be the process of construction and cognition of knowledge. The introduction of system of language and text has solved the communicative and objective validity of knowledge and made it possible to achieve the teaching and learning of knowledge. The largest community is mankind. As long as man exists, knowledge can be acquired. And at the meantime, knowledge can only be acquired under the condition of the existence of mankind (Ren, 2008).

Currently, the constructivist learning theory is widely used in the area of education and the activities of teaching. Analysis of and enlightenment from this theory may be expounded as follows: From the perspective of knowledge construction, knowledge is the understanding and hypothesis towards reality of an individual influenced by specific experience and culture. Different persons have different understandings towards the construction of knowledge. Thus, teachers pay attention to their students' individual characteristics and teach them according to their aptitude, so that each student can construct new knowledge according to their own cognitive level of knowledge. From the perspective of teaching, constructivists believe that learning is the active exploration of the student subject or the learning object so as to construct the process of understanding the object meaning. Therefore, teaching pivots on the meaningful construction of students by inspiring them to construct their own knowledge structure. From the perspective of learners, constructivists confirm that students are active constructors of meaning. So, during the process of teaching, teachers try their best to exert students' initiatives, emphasize the students' autonomy and help them actively discover, analyse and solve the problems in learning.

\section{B. Constructivist Teaching Mode and Teaching Design}

The constructivist learning theory emphasizes that students are the center of teaching and the subject of cognition. Teachers should adopt new teaching mode and carry out new teaching design in teaching process. Therefore, the new teaching mode and teaching design that are suitable to the constructivist learning theory are gradually formed.

1. Constructivist teaching mode

In the constructivist learning environment, compared with the traditional teaching method, the status of teachers and students has changed greatly. The constructivist learning theory emphasizes the opinion of students, taking students as the main body of cognition, and as the active constructors of the knowledge meaning. Teachers only help and promote 
the meaning construction of students and are not required to impart knowledge directly to students. Obviously, the constructivist learning theory advocates the student-centered learning under the guidance of teachers. Besides, constructivist learning environment includes four elements: situation, cooperation, conversation and meaning construction. To be more specific, the situation in the learning environment must be conducive to the students' construction of the meaning of what they have learned. Collaboration occurs throughout the learning process. It is very important for the collection and analysis of learning materials and the evaluation of learning outcomes and the final construction of meaning. Conversation is an integral part of collaborative learning process which should be discussed by the group members on how to complete the prescribed learning tasks. Meaning construction is the ultimate goal of the whole learning process. In the process of learning, teaching is harnessed to help students construct meaning, digest the content of the current study, and achieve a deep understanding of the inner link between one thing and some other things.

In summary, the teaching mode, based on the constructivist learning theory and constructivist learning environment, can be expounded as follows: In the course of the whole learning process, teachers play the role of organizer, mentor, helper and facilitator while students are placed at the center. Situation, cooperation and conversation are used as learning environment elements to completely stimulate the initiative, enthusiasm and the pioneering spirit of students. Thus, it can finally achieve the purpose of effectively realizing the meaning construction of the current knowledge (He, 1997).

2. Constructivist teaching design

In recent years, experts have made an extensive research and exploration in the field of education technology. They try to establish a new teaching design theory and method system which can adapt to constructivist learning theory and constructivist learning environment. It is a difficult task, and cannot be completed in a short term. But its basic ideas and main principles have become gradually clear and have been applied to the teaching design under the constructivist learning environment with aid of on multimedia and Internet. The teaching design principles can be summarized as follows: Firstly, there are three main elements, which are taking student as the center, externalizing knowledge and realizing self-feedback. Secondly, they emphasize the important role of situation in meaning construction. Through assimilation and adaptation, the construction of new knowledge can be achieved successfully. Thirdly, they focus on the key role of collaborative learning in meaning construction. Constructivists hold that the interaction between learners and the surrounding environment is very important in the understanding of learning content (i.e. the construction of knowledge). Fourthly, it emphasizes the design of the learning environment rather than the teaching environment. Constructivists strongly advocate that learning environment is a place where learners can explore freely and learn independently. Under this environment, students can use various tools and information resources, such as text materials, audio, video materials, CAI, multimedia courseware, Internet information to achieve their final learning goals. Teaching means more control and domination, while learning means more initiative and freedom. Fifthly, they favor the use of many information resources to support the idea that learning rather than teaching is more important and necessary. Media and information are not used to assist teachers in the presentation but to support students' autonomous learning and collaborative exploration. Last but not least, the final goal of the learning process is to accomplish the construction of meaning rather than to complete the teaching goal. According to the above analysis, the teaching design in the constructivist learning environment should contain the following contents and steps: Analysis of teaching aims, the creation of environment, information resource design, autonomous learning design, collaborative learning design, learning effect evaluation design and reinforcement practice design (He, 1997).

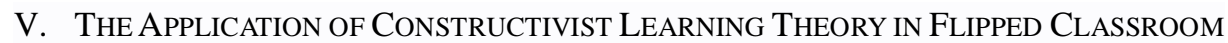

Flipped classroom teaching is the right embodiment of the constructivist learning theory. In other words, the constructivist learning theory can be practically applied to the flipped classroom teaching.

\section{A. The Role of Teachers and Students in Constructivism}

In the flipped classroom, the role of teachers and students is transformed. Teachers change their role into the facilitator and helper of students' learning while students become the main controller during their own learning process.

1. The role of teachers

In constructivism, the role of teachers is the faithful supporter of students' construction of knowledge. Teachers alter their role from traditional teaching into the facilitator and collaborator of students' learning. Teachers should devote themselves to provide students with some guidance. They also should create a good learning environment for students to expand their learning through cooperative learning and realize that teaching is a process of gradually reducing external control but increasing internal self-control of students. Besides, teachers should play the role of an active guide of students' construction of knowledge, not only stimulating their interests in pursuing knowledge but also keeping their learning motivation. Teachers play an important and indispensable part in students' pursuit of knowledge, and their construction of the knowledge they have learned so far. Consequently, teachers pay more attention to collaborative learning, discussion and communication in class, making the whole class beneficiaries in the process of constructing the meaning of knowledge.

2. The role of students 
In the teaching activities, students play the role of active participants and constructors of knowledge. Under the constructivist environment, students are confronted with a complex real-world situation and they are also required to complete a complex task in reality. Students adopt new learning styles and new cognitive processing strategy, forming a mental model in which he is both the builder and the reader of knowledge. Compared with the traditional mode of teaching, constructivist mode of teaching requires students to take more chances to manage their own learning independently. Students should use exploratory method and discovery method to construct the meaning of knowledge. As students play an important role, they need to actively collect and analyze the relevant information and resources, putting forward various hypotheses and try to verify the problems which they have learned. The center of teaching is transferred from the teacher to the student. The final goal of constructivist teaching is to cultivate lifelong learners. In addition, teachers and students are not in a vacuum, but in society. Therefore, parents, the designers and evaluators of the curriculum, relevant administrative personnel, and some other participants should change their ideology and actively face the learning and teaching revolution brought by constructivist (Wang, 2009).

\section{B. The Application of Constructivist Learning Theory in Self-directed Flipped Classroom}

\section{Self-directed flipped classroom}

Self-directed learning method is a kind of autonomous learning. In this method, individuals form their own learning needs and goals, and choose some proper learning strategies to acquire knowledge without the help of others. In flipped classroom, students' autonomy is fully reflected for the reason that flipped classroom is endowed with high degree of openness and flexibility, emphasizing on students' interaction. The core of flipped classroom is learning, which means that flipped classroom acknowledges students' autonomous and self-directed learning. American scholars first and most widely studied self-directed learning. Rubin, Holec, Candy et al. described the features of self-directed language learners as follows: They have their own typical learning styles, approaching the target language in a tolerant and open manner. They can also use state-of-the-art technology to deal with languages. They are willing to use the target language in a real environment and have the alternative strategies for testing and revising the target language. In self-directed learning mode, the learners are required to correctly assess and actively manage the learning targets, behavior, learning environment and the final results. From the point of most scholars' eyes, self-directed learning is considered the process of how to learn. Dickinson (1987) had his own special ideas about self-directed learning. He thought that was neither a process nor an ability, but an attitude. Holec thought that although self-directed learning means that the individual should have autonomy, this kind of ability may not be used or applied in the process of learning (Li, 2016).

2. The application of constructivist learning theory

In the flipped classroom, the teachers provide students with the teaching situation, teaching media, and teaching content, and assist students in actively exploring and completing the cognition and information processing. Students need to be active and creative in order to achieve learning targets in collaborative learning. Constructivist Learning Theory emphasizes that in the learning activities students are at the center position and are the active constructors of meaning. The main responsibility of teachers is to promote self-directed learning of students. Therefore, based on the Constructivist Learning Theory, in a student-directed flipped classroom, on the one hand, teachers carry on the corresponding training on the ability of autonomous learning through certain methods like using micro class. While on the other hand, emotionally teachers need to encourage students, giving them certain confidence in order to gradually cultivate the habit of self-learning. Under the Constructivist Learning Theory, in a flipped classroom self-directed learning mode, students learn how to learn, how to use knowledge and how to use the knowledge they have learned to solve complex problems, while the teacher systematically arranges courses for the purpose of integrating, exercising and refining complex ideas and learning techniques. It conforms to constructivist learning mode. Students participate in the learning activities entirely, and teachers help them master and know the learning targets, utilizing the classroom assessment to foster the teaching ( $\mathrm{Li}, 2016)$.

\section{Case Study on College English Teaching}

College English teaching covers many courses, of which comprehensive English course is a compulsory course for freshmen and sophomores in English major throughout the undergraduate fundamental education. It is also a comprehensive skill course at this stage cooperating with listening, speaking, reading and writing lessons. The course aims to cultivate students' logical thinking ability, hoping that through reading and analyzing language materials of the lessons, their minds can be broaden for sharp thinking, and solid professional foundation can be laid for the study of related courses. As comprehensive English course plays such an important role in college English teaching, the flipped classroom mode in this course can be taken out as a typical course to study the flipped classroom on college English teaching.

Vice President of Hangzhou Normal University of Foreign Languages, Li Ying tried the flipped classroom mode of self-directed learning and teaching in her own class of comprehensive English course in the second semester of freshman year because students are already familiar with the university environment at this stage, and the study pressure is not very high. She divided the students' tasks into three aspects: text, after-class extension, the explanation of main points of CET and TEM. The teacher provides the text comprehension PPT to the students' teaching group for reference, and students can add and subtract content according to their own judgment. For after-class extension, students need to 
select appropriate learning resources according to the text, including books, news, audio and video resources. For the explanation of main points of CET and TEM, the teacher urges the students to keep the habit of doing exercises frequently, explaining the key points of CET and TEM. In her lesson, she divided the whole class into eight groups and each group had three to four members. Each time, one group was responsible for teaching in any form as they like. Three of the students in the audience were observers, recording some details of the lectures and their own evaluations. In order to make the evaluation maintain objective continuity and varied perspectives, one of the three reviewers was permanent, that is to say, one student needs to record and evaluate each time, while the other two persons are in rotation. After the students' self-directed learning and flipped teaching mode had been implemented for half a semester, it was found that through self-assessment and mutual evaluation, students found their own gap, reflected on their own language learning process, and systematically sorted out the already grasped knowledge. Students surpassed themselves, demonstrating their learning ability, research ability and expression ability. Moreover, the study also found that students' ability of language output was much higher than that of other students in the same grade. Each group with joint efforts of all the members, tried to present a popular comprehensive English class under the guidance of the teacher. Students also experienced the achievements of self-management, self-regulation and group cooperation.

This mode has broken the traditional comprehensive English course mode which takes teachers and the classroom as the main body, focusing on patterns of teaching explicit language knowledge. The curriculum is built into a mode that based on students' language foundation and language skills, taking students as the main focuses. And under such mode of teaching, the participation of students in the whole process of learning is maximized, and students' independent learning ability has been greatly improved ( $\mathrm{Li}, 2016$ ). And this kind of flipping in comprehensive English class also corresponds with the core idea of constructivist learning theory which emphasizes the independence of students in learning and construction of knowledge and meaning. Students act as the main leader and controller of their own learning process, previewing the learning contents autonomously while teachers help students promote self-directed learning successfully.

\section{CONCLUSION}

The main feature of the constructivist learning theory is that it emphasizes the mode of students-centered learning. Students are seemed as an important and noticeable part in the process of English teaching of flipped classroom. Under the mode of constructivist learning theory, the students' subjective dynamic role is fully displayed. Students are the center of teaching activity, and teachers need to play the role of the organizer, helper, and mentor, only to assist students in the process of learning activities and students play the leading role in this type of classroom. Based on the constructivist learning theory, in the English teaching of flipped classroom, students are the main body of cognition, and the active constructors of meaning construction which breaks through the limitations of traditional classroom. Before class, students preheat the relevant knowledge through some media to carry on autonomous meaning construction.

At the same time, under the support of constructivist learning theory, the main responsibility of teachers is to promote self-directed learning of students. Teachers help students to carry out self-directed learning, regard students as the leader of the learning process, and cultivate students' learning independence. In terms of students themselves, they actively participate in teaching activities, complete self-learning, information integration, exploratory and collaborative learning and strive for self-meaning construction. They give full play to subjective initiative, and become the best controller and manager of self-learning process and activities. Moreover, with constructive learning method, students' learning motivation in English can be fully stimulated. It can arouse students' interests in learning and autonomous learning consciousness. In such a flipped classroom, students may set a long-term or short-term goal for themselves and spare no effort to achieve that goal which subtly change students' attitude and push them to learn actively and construct meaning with great enthusiasm.

In a word, constructivist learning theory is quite important in a flipped classroom. It plays a vital role in self-directed learning. It also has profound influence in the future development and promotion of flipped classroom both at home and abroad.

\section{REFERENCES}

[1] Abeysekera L. \& P. Dawson. (2014). Motivation and Cognitive Load in the Flipped Classroom: Definition, Rational and A Call for Research. Higher Education Research \& Development, 34, 1-14.

[2] Bergmann, J. \& Sams, A. (2012). Flip your classroom: Reach every student in every class every day. Eugene, Oregon: ISTE.

[3] Bishop, J. \& M. Verleger.(2013). The Flipped Classroom: A Survey of the Research. United States: Paper presented at the 120th ASEE Anual Conference \& Exposition, Atlanta, GA.

[4] Chen yi et al. (2014). Study on Teaching Design and Application Based on Flipped Classroom Model. Modern Educational Technology, 2, 49-54.

[5] Dai Xianglong. (2016). The Study on College Students' Learning Behavior in the Flipped Classroom. Yunnan: Yunnan Normal University, 20.

[6] Dickinson, L. (1987). Self-instruction in Language Learning. Cambridge: Cambridge University Press.

[7] Fang Qigui. (2017). Flipped Classroom and Micro-course Making Technology. Beijing: Tsinghua University Press, 20-25.

[8] Felder, R.M. (2012). Engineering education-A Tale of Two Paradigms. In SFGE, 2nd. Int Conf on Geotechnical Engineering Education, Galway. 
[9] Gordon, M. (2008). Between Constructivism and Connectedness. Journal of Teacher Education, 59(4), 322-331.

[10] He Kekang. (1997). Constructivism Teaching Mode, Method and Design. Journal of Beijing Normal University, 5, 75, 78-81.

[11] Kelly B. Butzler. (2014). The Effects of Motivation on Achievement and Satisfaction in a Flipped Classroom Learning Environment. United States: ProQuest Digital Dissertations, 1, 3, 17-18.

[12] Kim, K., M. Kim, O. Khera \& J. Getman. (2014). The Experience of Three Flipped Classroom in An Urban University: An Exploration of Design Principles. The Internet and Higher Education, 22, 37-50.

[13] Li Ying. (2016). Flipped classroom, Wise Teacher- Self-directed Learning in Foreign Language Classroom, Beijing: Foreign Language Teaching and Research Press.

[14] Luo Bin. (2012). Research on the Complementary Design of Network Teaching and Traditional Classroom Teaching. Technological innovation and application, 237-238.

[15] Neo et al. (2009). Engaging Students in Multimedia-mediated Constructivist Learning- Students' Perceptions. Educational Technology \& Society, 12(2), 254-266.

[16] Paul Barpule et al. (2014). It's Not about Seat Time:Blending,Flipping,and Efficiency in Active Learning Classrooms. Computers \& Education, 78, 227-236.

[17] Randall S. Davies, Douglas L. Dean, Nick Ball. (2013). Flipping the Classroom and Instructional Technology Integration in A College-level Information Systems Spreadsheet Course. Educational Technology Research and Development, 4, 565.

[18] Ren Youqun. (2008). Constructivism in Education. Beijing: Educational Science Publishing House, 20.

[19] Richard Pearce et al. (2012). Vodcasts and Active-learning Exercises in a"Flipped Classroom" Model of a Renal Pharmacotherapy Module. American Journal of Pharmaceutical Education, 76(10), 196-201.

[20] Wang Chaochao. (2017). An Explorative Research into the Effectiveness of College Students' Presentation in the Flipped Classroom Model. Hangzhou: Zhejiang University, 23.

[21] Wang Chun. (2009). Reorientation of Teacher-student Roles Based on Constructivism. China Electric Power Education, 148, 29-30.

[22] Wang Lina, Huang Qiusheng, Jiang Yi. (2017). A Comparative Analysis of the Current Situation of Flipped Classroom at Home and Abroad. Digital Education, 2, 19-21.

[23] Zhao Xinglong. (2014). The Process of Knowledge Internalization and the Design of Teaching Mode in Flipped Classroom. Modern Distance Education Research, 2, 55-61.

[24] Zhang Jinlei. (2013). The Application of Gamification Learning Concept in Flipped Classroom Teaching. Journal of Distance Education, 1, 73-78.

Ziling Xu was born in Quzhou, China in 1997. She is currently a junior student of Zhejiang Ocean University, specializing in English major for education. Her research interest focuses on English teaching.

Yeli Shi was born in Zhejiang, China. She received her Master's degree in foreign language and literature from Zhejiang University, China in 2005. She is currently an associate Professor of Foreign Language College, Zhejiang Ocean University, China. Her research interests include cross-culture communication, metaphor, and English teaching. 